\title{
Hepatitis C for Primary Care Physicians
}

\author{
Miranda M. Huffman, MD, MEd, and Anne L. Mounsey, MD
}

Hepatitis $\mathrm{C}$ is a common cause of cirrhosis, hepatocellular carcinoma, and liver transplant. Although it is usually asymptomatic, new screening recommendations will lead to increased recognition by primary care physicians. Rapidly evolving treatment recommendations are making this a treatable infection for many patients. Recognition of the infection and initiation of treatment for appropriate patients will decrease the likelihood of progression to cirrhosis and hepatocellular carcinoma. Primary care physicians have the difficult task of managing comorbid conditions, such as chronic pain and hyperlipidemia, in patients with hepatitis $\mathrm{C}$, as well as a potential for treating hepatitis $\mathrm{C}$. ( $\mathrm{J}$ Am Board Fam Med 2014;27: 284-291.)

Keywords: Gastrointestinal Disorders, Hepatitis C

Hepatitis $\mathrm{C}$ is the leading cause of liver transplant in the United States and a common cause of cirrhosis and hepatocellular carcinoma. ${ }^{1,2}$ An estimated 4.1 million individuals, or $1.6 \%$ of the population, are infected nationwide, many of whom are unaware of the infection since it is often asymptomatic. ${ }^{3}$ Hepatitis $\mathrm{C}$ is a bloodborne infection, most commonly transmitted by intravenous drug use. $^{2}$

\section{Screening for Hepatitis C}

Screening for hepatitis $\mathrm{C}$ should be considered in patients who are at risk for infection or who have known exposure (Table 1). The Centers for Disease Control and Prevention and the US Prevention Services Task Force recommends one-time screening for people born between 1945 and 1965 because of the high rate of undiagnosed infection in this population who may have been exposed before universal precautions were implemented and do

This article was externally peer reviewed.

Submitted 23 May 2013; revised 31 August 2013; accepted 6 September 2013.

From the Department of Community and Family Medicine, University of Missouri-Kansas City (MMH); and the Department of Family Medicine, University of North Carolina at Chapel Hill (ALM).

Funding: none.

Conflict of interest: none declared.

Corresponding author: Miranda Huffman, MD, MEd, Department of Community and Family Medicine, University of Missouri-Kansas City, 2301 Charlotte St., Kansas City, MO 64108 (E-mail: miranda.huffman@tmcmed.org). not recall or report risk factors to their primary care providers. ${ }^{4-6}$ Screening patients with risk factors for hepatitis $\mathrm{C}$ has a sensitivity of $90 \%$, with a number needed to screen to identify one case of hepatitis $\mathrm{C}$ of $<20{ }^{7}$

\section{Clinical Presentation}

Jaundice, abdominal pain, or, more commonly, nonspecific flu-like symptoms such as fatigue, muscles aches, and nausea occur in $25 \%$ to $30 \%$ of patients when they are infected with hepatitis C, but most patients are asymptomatic. ${ }^{8}$ During this period, alanine aminotransferase and aspartate aminotransferase levels increase rapidly, often to 10 times the upper limit of normal. ${ }^{9}$

Approximately $50 \%$ to $80 \%$ of patients infected with hepatitis $\mathrm{C}$ progress to chronic infection, defined as a persistence of the virus for $>6$ months after the initial infection. ${ }^{2}$ Chronic hepatitis $\mathrm{C}$ is usually asymptomatic and often is found during investigation for an incidental finding of elevated liver transaminases. When symptomatic, patients with chronic hepatitis $\mathrm{C}$ present with nonspecific symptoms such as nausea, anorexia, and fatigue or signs of cirrhosis on examination.

Hepatitis $\mathrm{C}$ has been reported to cause numerous extrahepatic manifestations, although the association for many of the conditions has been questioned. ${ }^{10}$ Hepatitis $\mathrm{C}$ can cause both mixed cryoglobulinemia and B-cell non-Hodgkin's lymphoma ${ }^{11}$ and may have a role in certain rheumato- 
Table 1. Factors Influencing Patients at High Risk for Hepatitis C Infection ${ }^{5}$

\begin{tabular}{ll}
\hline High Risk of Exposure & \multicolumn{1}{c}{ Known Exposure } \\
\hline $\begin{array}{l}\text { History of IV drug use or current IV drug user } \\
\text { History of incarceration }\end{array}$ & $\begin{array}{l}\text { Sexual partners and household contacts infected with hepatitis C } \\
\text { Infants born to mothers infected with hepatitis C }\end{array}$ \\
$\begin{array}{l}\text { Blood transfusion or solid-organ transplant before screening } \\
\quad \text { for hepatitis C (1992) }\end{array}$ & $\begin{array}{l}\text { Health care workers with needle-stick exposure } \\
\text { Patients with hemophilia who received clotting factor } \\
\text { transfusion before 1987 }\end{array}$ \\
$\begin{array}{l}\text { Hemodialysis patients } \\
\text { HIV-positive patients } \\
\text { More than 20 sexual partners within lifetime }\end{array}$ \\
\hline
\end{tabular}

IV, intravenous; HIV, Human Immunodeficiency Virus.

logic, endocrine, and dermatologic conditions such as rheumatoid arthritis and dermatomyositis. ${ }^{10,11}$

\section{Diagnosis}

In patients with acute hepatitis $\mathrm{C}$, hepatitis $\mathrm{C}$ virus (HCV) RNA can be detected as early as 7 days after exposure, but the antibody to HCV (anti-HCV) may not be present until 6 to 8 weeks after exposure. ${ }^{9}$ Chronic hepatitis $\mathrm{C}$ is diagnosed when both anti-HCV and HCV RNA are present (Figure 1). ${ }^{9}$ Anti-HCV is the appropriate laboratory test to order when screening for hepatitis $\mathrm{C}$ in asymptomatic patients; hepatitis $\mathrm{C}$ is confirmed by the presence of HCV RNA. ${ }^{6}$

\section{Initial Evaluation of Patients With Chronic Hepatitis C}

To determine whether a patient is a potential candidate for treatment, they must be evaluated for contraindications to treatment and disease severity (Tables 2 and 3). Patients have traditionally required a liver biopsy to determine the severity of liver disease, although the utility of liver biopsy has recently been called into question because it carries a small but real risk of complications. ${ }^{2}$ Serum tests and ultrasonography may assist in defining disease severity but are not recommended by current guidelines. $^{14}$

Patients with compensated cirrhosis (bilirubin $<1.5 \mathrm{~g} / \mathrm{dL}$, international normalized ratio (INR) $<1.5$, albumin $>3.4 \mathrm{~g} / \mathrm{dL}$, platelets $>75,000 \mathrm{k} / \mathrm{mm} 3$, and no evidence of ascites or hepatic encephalopathy) or fibrosis on liver biopsy should be offered treatment for chronic hepatitis C. ${ }^{2}$ Current treatment guidelines stress that the decision to treat should be individualized based on the patient's overall health and personal preferences. Therefore, while the data sug- gest that patients without evidence of fibrosis or cirrhosis on biopsy have a low risk for liver-related complications or death in the next 10 to 20 years, some may still elect to pursue treatment. ${ }^{2}$ Patients who elect not to pursue treatment may be monitored with annual assessment using liver function and consideration of biopsy if aminotransferase levels increase. $^{2}$

\section{Treatment}

Hepatitis $\mathrm{C}$ is treated to lower the risk of progression to end-stage liver disease or hepatocellular carcinoma. The goal of treatment is a sustained decrease in hepatitis C viral RNA (called the sustained virological response [SVR]), which is defined as no detectable hepatitis C viral RNA 24 weeks after treatment. ${ }^{2}$ Studies have found that SVR is linked with a $30 \%$ to $50 \%$ decrease in all-cause mortality. ${ }^{15}$

The treatment regimen depends on the genotype of the virus. For genotype 1, the most common type in the United States, patients are treated with triple therapy, which includes pegylated interferon- $\alpha$, ribavirin, and either boceprevir and telaprevir, which are direct-acting protease inhibitors. ${ }^{2,16,17}$ The addition of the direct-acting protease inhibitors significantly increases the likelihood of successful treatment as determined by SVR in patients infected with genotype 1 and shortens the duration of treatment for some patients. ${ }^{16}$ While the 2 agents have equal efficacy, telaprevir has a simpler dosing schedule and for that reason is discussed in detail here (Table 4 and Figure 2). Patients with genotypes 2 to 6 are treated with pegylated interferon and ribavirin at a dosage of $800 \mathrm{mg}$ daily for 24 weeks. ${ }^{17}$

Both protease inhibitors have multiple drug interactions and should be checked against all of a patient's current medications. ${ }^{16}$ Anemia is a fre- 
Figure 1. Diagnosing hepatitis C. EIA, enzyme immunoassay; RNA, ribonucleic acid; PCR, polymerase chain reaction. ${ }^{2,8}$

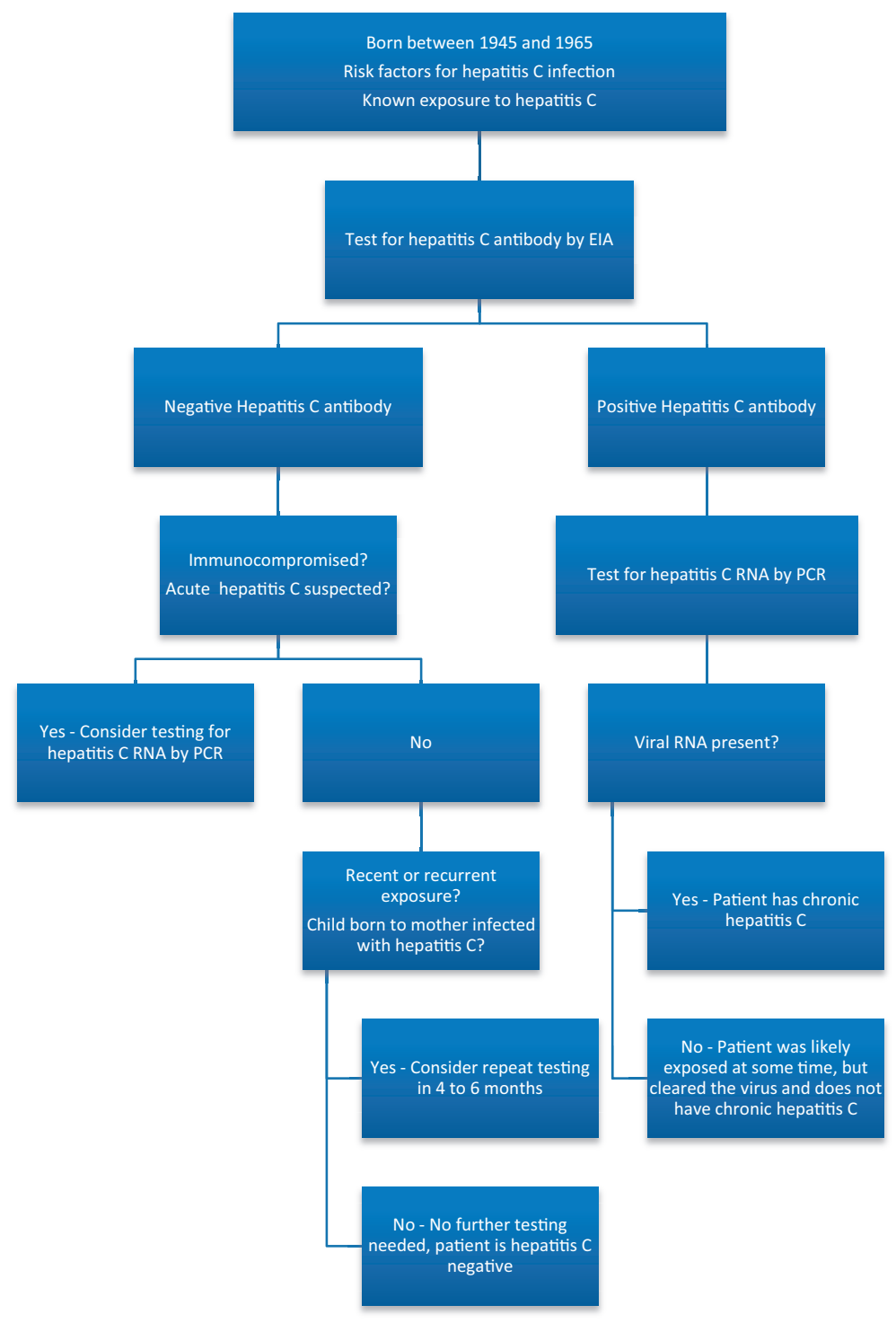

quent complication of treatment, occurring in as many as $49 \%$ of patients treated with protease inhibitors, and it may be treated by reducing the dose of ribavirin. ${ }^{16}$ Other common side effects of treatment include rash, pruritus, nausea, and diarrhea. ${ }^{16}$

The treatment of hepatitis $\mathrm{C}$ is rapidly evolving, with $>40$ drugs in development, including interferon and ribavirin analogs, vaccines, immunomodulators, and direct-acting antiviral drugs. ${ }^{18}$ As the treatment of hepatitis $\mathrm{C}$ continues to evolve, primary care physicians may also have a more active role in the treatment of hepatitis $\mathrm{C}$, and some locations are already doing so with the assistance of telemedicine. ${ }^{19,20}$

\section{Primary Care for Patients with Chronic Hepatitis C}

Patients who are not immune to hepatitis A or B should receive vaccination. ${ }^{21,22}$ Patients with cirrhosis should also be offered pneumococcal vaccination and annual inactivated influenza vaccination. $^{23}$

All patients with chronic hepatitis $\mathrm{C}$ should be advised to abstain from drinking alcohol to decrease the risk of cirrhosis, and referral to treatment facilities should be provided. ${ }^{24}$ Alcohol significantly increases the risk of the development of cirrhosis in patients with hepatitis $\mathrm{C}$, with an odds ratio of 147.2 (95\% confidence interval [CI], 42.1514.3) for heavy drinkers (eg, $>175 \mathrm{~g}$ per day 
Table 2. Absolute and Relative Contraindications for Treatment of Hepatitis $\mathbf{C}^{2}$

\begin{tabular}{ll}
\hline Absolute Contraindications* $^{*}$ & \multicolumn{1}{c}{ Relative Contraindications $^{\dagger}$} \\
\hline $\begin{array}{l}\text { Major uncontrolled depressive illness } \\
\text { Untreated thyroid disease }\end{array}$ & $\begin{array}{l}\text { Failed prior treatment (nonresponders and relapsers) } \\
\text { Current users of illicit drugs or alcohol who are willing to } \\
\text { participate in a substance abuse program or alcohol } \\
\text { support program }\end{array}$ \\
$\begin{array}{l}\text { Solid-organ transplant (renal, heart, or lung) } \\
\text { Autoimmune hepatitis or other autoimmune condition known no or mild fibrosis on liver biopsy }\end{array}$ & Acute hepatitis C \\
to be exacerbated by peginterferon and ribavirin & Coinfection with HIV \\
$\begin{array}{l}\text { Pregnant or unwilling to comply with adequate contraception } \\
\text { Severe concurrent medical disease such as severe } \\
\text { hypertension, heart failure, significant coronary heart } \\
\text { disease, poorly controlled diabetes, chronic obstructive } \\
\text { pulmonary disease }\end{array}$ & $\begin{array}{l}\text { Younger than 18 years of age } \\
\text { Age }<2 \text { years }\end{array}$ \\
$\begin{array}{l}\text { Known hypersensitivity to drugs used to treat hepatitis C } \\
\text { virus }\end{array}$ & $\begin{array}{c}\text { Chronic renal disease (either requiring or not requiring } \\
\text { hemodialysis) }\end{array}$ \\
\hline
\end{tabular}

*Therapy is currently contraindicated.

${ }^{\dagger}$ Therapy should be individualized.

抽 Treatment may be considered after depression and thyroid disease are medically stable.

HIV, Human Immunodeficiency Virus.

averaged over the lifetime). ${ }^{25}$ Even moderate drinking can increase the risk for progression to cirrhosis in some patients. ${ }^{26}$ Intravenous drug

Table 3. Initial Testing for Patients With New Diagnosis of Hepatitis C by Primary Care Providers

Evaluation of disease severity

Quantitative HCV RNA level

$\mathrm{HCV}$ genotype

Serum aminotransferase levels

Coagulation studies

Complete blood count

Liver biopsy (optional)

Liver ultrasound (optional)

Hepatitis B surface antigen

Ferritin level

Evaluation for contraindications to treatment

Depression screening instrument, such as PHQ- $9^{12}$

Alcohol abuse screening test, such as AUDIT-C ${ }^{13}$

Urine drug screen

Urine hCG in women of childbearing age

HIV antibody

Creatinine

Thyroid function tests

Antinuclear antibody to evaluate for autoimmune hepatitis

Health maintenance

Hepatitis A antibody

Hepatitis B surface antibody

AUDIT-C, AUDIT Alcohol Consumption Questionnaire; hCG, human chorionic gonadotropin; HCV, hepatitis C virus; PHQ-9, 9-item Patient Health Questionnaire; RNA, ribonucleic acid. abusers should be referred for appropriate addiction treatment. Obesity is a risk factor for progression of liver disease because of the development of nonalcoholic steatohepatitis syndrome, so assistance with weight loss should be provided to obese patients. ${ }^{27}$

Patients should be counseled about behaviors to reduce the risk of transmission, including avoiding the donation of blood and plasma. The risk of transmission of hepatitis $C$ by sexual activity in monogamous heterosexual couples is low (approximately $0.07 \%$ per year; 95\% CI, 0.01$0.13 \%)$, and condom use is not necessary in these couples. ${ }^{28}$ Sexual transmission may occur at a higher rate in men who have sex with men, especially those infected with HIV. ${ }^{29}$ Patients should be counseled to avoid sharing toothbrushes, razors, and other items that may be contaminated with blood.

Chronic hepatitis $\mathrm{C}$ infection should not be considered a contraindication to treatment with HMGcoenzyme A reductase inhibitors (statins) ${ }^{30}$ and may even be an option for the treatment of hepatitis $\mathrm{C}$ in the future. ${ }^{31,32}$ Statins should be avoided if there is evidence of hepatic failure, such as jaundice or increased bilirubin level. ${ }^{33}$ Patients with elevated serum aminotransferase levels ( $>3$ times baseline or $>5$ times the upper limits of normal) should not be taking statins, although they could be started if levels fall. ${ }^{34}$ 
Table 4. Triple Therapy Dosing Regiments Based on Type of Peginterferon Selected

\begin{tabular}{llc}
\hline Therapy & Regimen 1 & Regimen 2 \\
\hline Telaprevir & $750 \mathrm{mg}$ every 8 hours with a non-low-fat meal & 750 mg every 8 hours with a non-low-fat meal \\
Peginterferon- $\alpha$ & $2 \mathrm{a} ; 180 \mu \mathrm{g}$ subcutaneously every week & $2 \mathrm{~b} ; 1.5 \mu \mathrm{g} / \mathrm{kg}$ subcutaneously every week \\
Ribavirin & $1000 \mathrm{mg}$ daily if $<75 \mathrm{~kg}$ & $800 \mathrm{mg}$ daily if $<65 \mathrm{~kg}$ \\
& $1200 \mathrm{mg}$ daily if $>75 \mathrm{~kg}$ & $1000 \mathrm{mg}$ daily if $>65$ and $<85 \mathrm{~kg}$ \\
& & $1200 \mathrm{mg}$ daily if $>85 \mathrm{~kg}$ and $<105 \mathrm{~kg}$ \\
& $1400 \mathrm{mg}$ daily if $>105 \mathrm{~kg}$ \\
\hline
\end{tabular}

Treatment of pain in patients with cirrhosis can be particularly problematic. Many providers avoid using acetaminophen in patients with chronic liver disease because of the potential for hepatotoxicity. However, at therapeutic doses of
$<4$ g/day, acetaminophen is generally considered safe, although some experts recommend a lower dose of 2 g/day. ${ }^{35,36}$ Nonsteroidal anti-inflammatories should be avoided in patients with cirrhosis because of the potential for hepatorenal syn-

Figure 2. Treatment of chronic hepatitis C genotype 1 with telaprevir-based therapy. Dual therapy, peginterferon + ribavirin; HCV, hepatitis C virus; RNA, ribonucleic acid; triple therapy, telaprevir + peginterferon + ribavirin (see Table 4 for dosing).

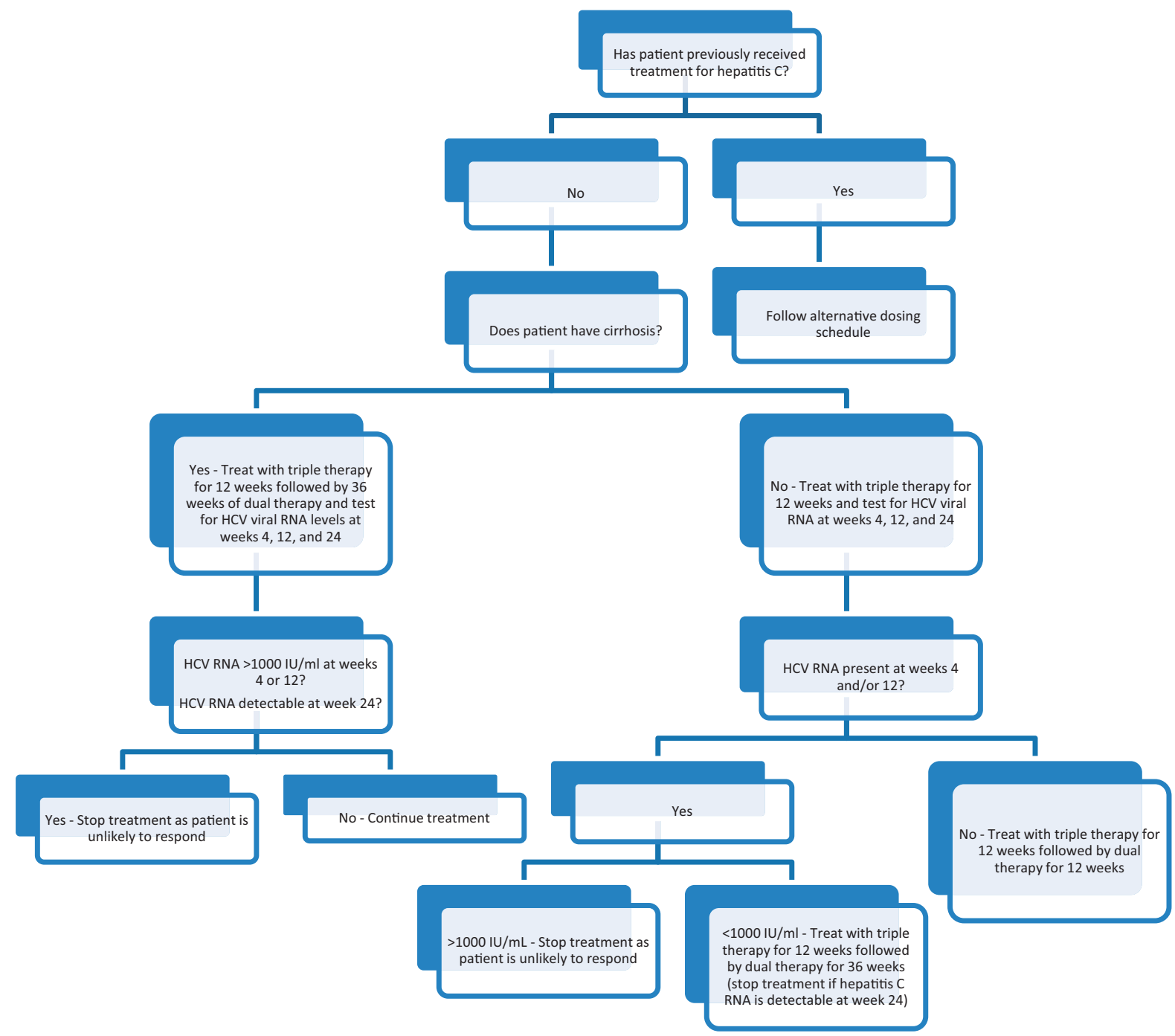


Patients born between 1945 and 1965 or with risk factors should be screened for hepatitis C.

Patients for whom there is no contraindication should be offered treatment for hepatitis C.

Patients with the hepatitis $\mathrm{C}$ genotype 1 should be treated with triple therapy (peginterferon- $\alpha$, ribavirin, and

Patients without documented immunity to hepatitis A and B should be offered vaccination.

Patients with chronic hepatitis $\mathrm{C}$ should be encouraged to abstain from alcohol and offered treatment if needed.

Nonsteroidal anti-inflammatory drugs should be avoided in patients with cirrhosis. Acetaminophen and opioids can be used at low doses if needed.

Statin drugs may be used in patients with hepatitis $\mathrm{C}$ if serum aminotransferase levels are $<5$ times the upper limit of normal.

Patients with cirrhosis due to hepatitis $\mathrm{C}$ should be screened for hepatocellular carcinoma with annual ultrasound testing.

drome or gastrointestinal bleeding. ${ }^{37,38}$ Because of impairment in drug metabolism, the use of opioids should be minimized since they can precipitate hepatic encephalopathy. If opioids are necessary for adequate analgesia, the minimum effective dose should be used and longer intervals between administrations should be considered. ${ }^{39}$

Primary care physicians may also be asked to manage depression induced by treatment with interferon- $\alpha$. In general, treatment with selective serotonin reuptake inhibitors can be initiated as soon as patients begin to manifest symptoms of depression. ${ }^{40}$ Several small trials have investigated the use of selective serotonin reuptake inhibitors for the prevention of depression, with mixed results. ${ }^{41}$ Therefore, current data support waiting for symptoms to develop rather than using pretreatment.

Patients who have both hepatitis $\mathrm{C}$ and cirrhosis are at increased risk of developing hepatocellular carcinoma and should be offered screening by annual or semiannual ultrasound. $\alpha$-Fetoprotein levels alone should not be used for screening unless ultrasound is unavailable. ${ }^{42}$ Current guidelines also recommend continued screening for patients who have been successfully treated for hepatitis $\mathrm{C}$ and patients who have evidence of bridging fibrosis on liver biopsy, although the data of efficacy lag behind the recommendation. ${ }^{42}$

\section{Conclusion}

With emerging recommendations to screen for asymptomatic hepatitis $\mathrm{C}$ in patients born between 1945 and 1965, family physicians will increasingly be responsible for the diagnosis and management of infected patients. Ordering appropriate laboratory work and maximizing control of chronic conditions before initiating referrals can help ensure selected patients receive prompt treatment. Primary care providers can work with gastroenterologists and infectious disease specialists to ensure patients receive appropriate vaccinations, lifestyle counseling, and screening tests (Table 5).

\section{References}

1. Lauer GM, Walker BD. Hepatitis C virus infection. N Engl J Med 2001;345:41-52.

2. Ghany MG, Strader DB, Thomas DL, Seeff LB; American Association for the Study of Liver Diseases. Diagnosis, management, and treatment of hepatitis C: an update. Hepatology 2009;49:1335-74.

3. Armstrong GL, Wasley A, Simard EP, McQuillan GM, Kuhnert WL, Alter MJ. The prevalence of hepatitis C virus infection in the United States, 1999 through 2002. Ann Intern Med 2006;144:705-14.

4. Smith BD, Morgan RL, Beckett GA, et al. Centers for Disease Control and Prevention. Recommendations for the identification of chronic hepatitis $\mathrm{C}$ virus infection among persons born during 19451965. MMWR Recomm Rep 2012;61(RR-4): $1-32$.

5. Recommendations for prevention and control of hepatitis $\mathrm{C}$ virus (HCV) infection and $\mathrm{HCV}$-related chronic disease. Centers for Disease Control and Prevention. MMWR Recomm Rep 1998;47(RR-19): $1-39$.

6. Moyer VA; U.S. Preventive Services Task Force. Screening for hepatitis $\mathrm{C}$ virus infection in adults: U.S. Preventive Services Task Force recommendation statement. Ann Intern Med 2013;159: $349-57$. 
7. Chou R, Cottrell EB, Wasson N, et al. Screening for hepatitis $\mathrm{C}$ virus infection in adults. Comparative effectiveness reviews, no. 69 [Internet]. Rockville (MD): Agency for Healthcare Research and Quality; November 2012. Available from: http://www.ncbi. nlm.nih.gov/books/NBK115428/. Accessed January 22, 2014.

8. Kamal SM. Acute hepatitis C: a systematic review. Am J Gastroenterol 2008;103:1283-97.

9. Thomas D, Seeff L. Natural history of hepatitis C. Clin Liver Dis 2005;9:383-98.

10. Agnello V, De Rosa FG. Extrahepatic disease manifestations of $\mathrm{HCV}$ infection: some current issues. J Hepatol 2004;40:341-52.

11. Zignego AL, Craxì A. Extrahepatic manifestations of hepatitis C virus infection. Clin Liver Dis 2008;12: 611-36.

12. Kroenke K, Spitzer RL, Williams JB. The PHQ-9: validity of a brief depression severity measure. J Gen Intern Med 2001;16:606-13.

13. Bush K, Kivlahan DR, McDonell MB, Fihn SD, Bradley KA. The AUDIT Alcohol Consumption Questionnaire (AUDIT-C): an effective brief screening test for problem drinking. Arch Intern Med 1998;158:1789-95.

14. Fontana RJ, Lok AS. Noninvasive monitoring of patients with chronic hepatitis C. Hepatology 2002; 36(5 Suppl 1):S57-64.

15. Backus LI, Boothroyd DB, Phillips BR, Belperio P, Halloran J, Mole LA. A sustained virologic response reduces risk of all-cause mortality in patients with hepatitis C. Clin Gastroenterol Hepatol 2011;9: 509-16.e1.

16. Ghany MG, Nelson DR, Strader DB, Thomas DL, Seeff LB. An update on treatment of genotype 1 chronic hepatitis $\mathrm{C}$ virus infection: 2011 practice guideline by the American Association for the Study of Liver Diseases. Hepatology 2011;54:1433-44.

17. Liang TJ, Ghany MG. Current and future therapies for hepatitis C virus infection. N Engl J Med 2013; 368:1907-17.

18. Lee LY, Tong CY, Wong T, Wilkinson M. New therapies for chronic hepatitis $\mathrm{C}$ infection: a systematic review of evidence from clinical trials. Int $\mathrm{J}$ Clin Pract 2012;66:342-55.

19. Arora S, Thornton K, Murata G, et al. Outcomes of treatment for hepatitis $\mathrm{C}$ virus infection by primary care providers. N Engl J Med 2011;364:2199-207.

20. Khatri K, Haddad M, Anderson D. Project ECHO: replicating a novel model to enhance access to hepatitis $\mathrm{C}$ care in a community health center. J Health Care Poor Underserved 2013;24:850-8.

21. Shim M, Khaykis I, Park J, Bini EJ. Susceptibility to hepatitis A in patients with chronic liver disease due to hepatitis $\mathrm{C}$ virus infection: missed opportunities for vaccination. Hepatology 2005;42:688-95.

22. Tsai JF, Jeng JE, Ho MS, Chang WY, Lin ZY, Tsai JH. Independent and additive effect modifi- cation of hepatitis $C$ and $B$ viruses infection on the development of chronic hepatitis. J Hepatol 1996; 24:271-6.

23. Centers for Disease Control and Prevention (CDC). Use of 13-valent pneumococcal conjugate vaccine and 23 -valent pneumococcal polysaccharide vaccine for adults with immunocompromising conditions: recommendations of the Advisory Committee on Immunization Practices (ACIP). MMWR Morb Mortal Wkly Rep 2012;61:816-9.

24. Wiley TE, McCarthy M, Breidi L, McCarthy M, Layden TJ. Impact of alcohol on the histological and clinical progression of hepatitis $\mathrm{C}$ infection. Hepatology 1998;28:805-9.

25. Corrao G, Aricò S. Independent and combined action of hepatitis $\mathrm{C}$ virus infection and alcohol consumption on the risk of symptomatic liver cirrhosis. Hepatology 1998;27:914-9.

26. Westin J, Lagging LM, Spak F, et al. Moderate alcohol intake increases fibrosis progression in untreated patients with hepatitis $\mathrm{C}$ virus infection. J Viral Hepat 2002;9:235-41.

27. Ortiz V, Berenguer M, Rayon JM, Carrasco D, Berenguer J. Contribution of obesity to hepatitis C-related fibrosis progression. Am J Gastroenterol 2002; 9:2408-14.

28. Terrault NA, Dodge JL, Murphy EL, et al. Sexual transmission of HCV among monogamous heterosexual couples: the HCV Partners Study. Hepatology 2013;57:881-9.

29. Tohme RA, Holmberg SD. Is sexual contact a major mode of hepatitis $\mathrm{C}$ virus transmission? Hepatology 2010;52:1497-505.

30. Onofrei MD, Butler KL, Fuke DC, Miller HB. Safety of statin therapy in patients with preexisting liver disease. Pharmacotherapy 2008;28:522-9.

31. Bader T, Fazili J, Madhoun M, et al. Fluvastatin inhibits hepatitis $\mathrm{C}$ replication in humans. Am J Gastroenterol 2008;103:1383-9.

32. Rao GA, Pandya PK. Statin therapy improves sustained virologic response among diabetic patients with chronic hepatitis C. Gastroenterology 2011; 140:144-52.

33. Tzefos M, Olin JL. 3-Hydroxyl-3-methylglutaryl coenzyme A reductase inhibitor use in chronic liver disease: a therapeutic controversy. J Clin Lipidol 2011;5:450-9.

34. Calderon RM, Cubeddu LX, Goldberg RB, Schiff ER. Statins in the treatment of dyslipidemia in the presence of elevated liver aminotransferase levels: a therapeutic dilemma. Mayo Clin Proc 2010;85: 349-56.

35. Benson GD, Koff RS, Tolman KG. The therapeutic use of acetaminophen in patients with liver disease. Am J Ther 2005;12:133-41.

36. Mehta G, Rothstein KD. Health maintenance issues in cirrhosis. Med Clin North Am 2009;93:901-15, viii-ix. 
37. Castro-Fernández M, Sánchez-Muñoz D, Galán-Jurado $M V$, et al. Influence of nonsteroidal antiinflammatory drugs in gastrointestinal bleeding due to gastroduodenal ulcers or erosions in patients with liver cirrhosis. Gastroenterol Hepatol 2006;29:11-4.

38. Laffi G, La Villa G, Pinzani M, Marra F, Gentilini P. Arachidonic acid derivatives and renal function in liver cirrhosis. Semin Nephrol 1997;17:530-48.

39. Hirschfield GM, Kumagi T, Heathcote EJ. Preventative hepatology: minimising symptoms and optimising care. Liver Int 2008;28:922-34.
40. Asnis GM, De La Garza R 2nd. Interferon-induced depression in chronic hepatitis $\mathrm{C}$ : a review of its prevalence, risk factors, biology, and treatment approaches. J Clin Gastroenterol 2006;40:322-35.

41. Morasco BJ, Rifai MA, Loftis JM, et al. A randomized trial of paroxetine to prevent interferon-alphainduced depression in patients with hepatitis C. J Affect Disord 2007;103:83-90.

42. Bruix J, Sherman M. Management of hepatocellular carcinoma. Hepatology 2005;42:1208-36. 